\title{
LUPUS ERITEMATOSO SISTÉMICO AMPOLLOSO
}

\section{Reporte de un caso y revisión de la literatura}

José Ignacio Hernandez. MD. ", Sandra Lucia Suárez Delgado MD. **

Se describe el caso de una mujer de 19 años de edad, natural y procedente de Bogotá, hospitalizada por el servicio de Medicina Interna del Hospital de San José, que se desempeñaba como empleada del servicio domestico, a quien cinco meses antes de su ingreso se le realizó diagnostico de (LES), momento en el cual cursaba con 11 semanas de gestación.

Desde su inicio la enfermedad se manifestó, además de eritema malar, artralgias, ulceras orales, astenia y adinamia, por lesiones vesicoampollosas localizadas en extremidades, mucosas vaginal y oral. Estas últimas persisten hasta la actualidad, en forma intermitente (Figuras 1 a 3).

Dentro de los estudios realizados se documentó ANAS positivos con títulos de 1/800, complemento consumido $\left(\mathrm{C}_{3}<30, \mathrm{C}_{4}<4,5\right)$, anti-DNA elevado (956 $\mathrm{UI} / \mathrm{ml}$ ), anemia microcítica hipocrómica con hemoglobina de $9,8 \mathrm{~g} / \mathrm{dl}$ y linfopenia $\left(600\right.$ linfocitos $\left./ \mathrm{mm}^{3}\right)$. Durante su evolución presenta adenopatía cervical, cuya biopsia reportó linfadenopatía asociada con LES activo. Con tratamiento de prednisona a $1 \mathrm{mg} / \mathrm{k} / \mathrm{d}$ presenta mejoría de la sintomatología descrita, excepto por las lesiones en piel.

A las 24 semanas de gestación experimenta parto pretérmino y dos semanas después consulta por exacerbación de manifestaciones cutáneas.

Al examen físico hay lesiones ampollosas de más o menos $6 \mathrm{~cm}$ de diámetro en las cuatro extremidades, sin compromiso de mucosas. Es valorada por el servicio de dermatología y consideran como posibilidades

Departamento de Medicina Interna. Hospital de San José.

Residente de Medicina Interna. Hospital de San José.

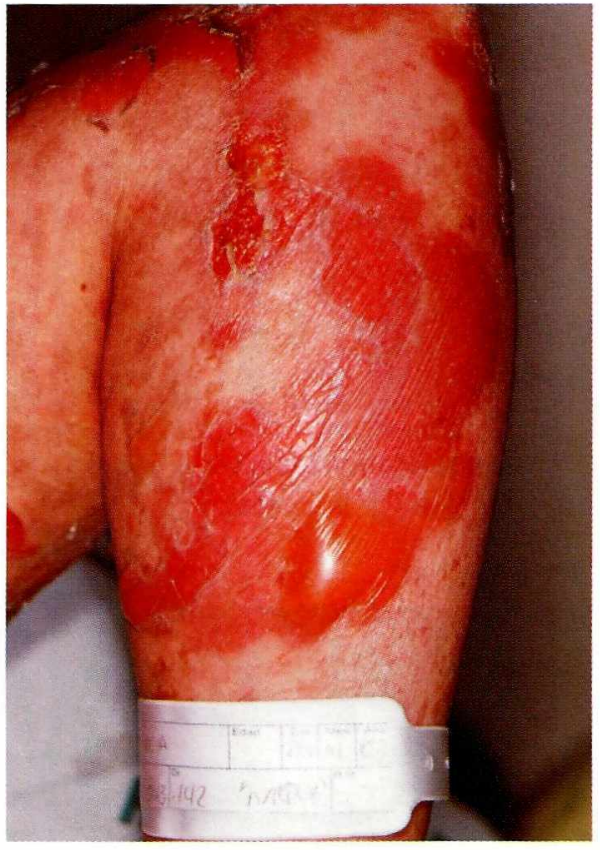

Figura I. Lesiones ampollosas con base eritematosa en la cara interna del antebrazo derecho. (Cortesía del Dr. Juan J. Atuesta).

diagnósticas penfigoide gestacional o lupus eritematoso ampolloso.

Se realizó biopsia de piel sana y comprometida, con el fin de aclarar el diagnóstico (Figura 4). La inmunofluorescencia de piel no expuesta demuestra IgG puntiforme basal $(++++)$, fibrinógeno puntiforme basal $(+), \mathrm{C}_{1 \mathrm{q}}(++++), \mathrm{C}_{3}(+), \mathrm{C}_{4}(-), \operatorname{IgM}(+)$ e $\operatorname{Ig} \mathrm{A}(+) . \mathrm{En}$ piel no expuesta los resultados son: $\mathrm{IgG}(++++)$, fibrinógeno (+++), $\mathrm{C}_{1 \mathrm{q}}(++++), \mathrm{C}_{3}(+++), \mathrm{C}_{4}(-), \operatorname{IgM}$ (+) e IgA (+). Tales parámetros son diagnósticos de LES ampolloso, por lo cual se realizó manejo inicial con pulsos de metilprednisolona y azatioprina.

La evolución clínica es hacia la mejoría, con desaparición de las lesiones cutáneas descritas. Se autorizó 


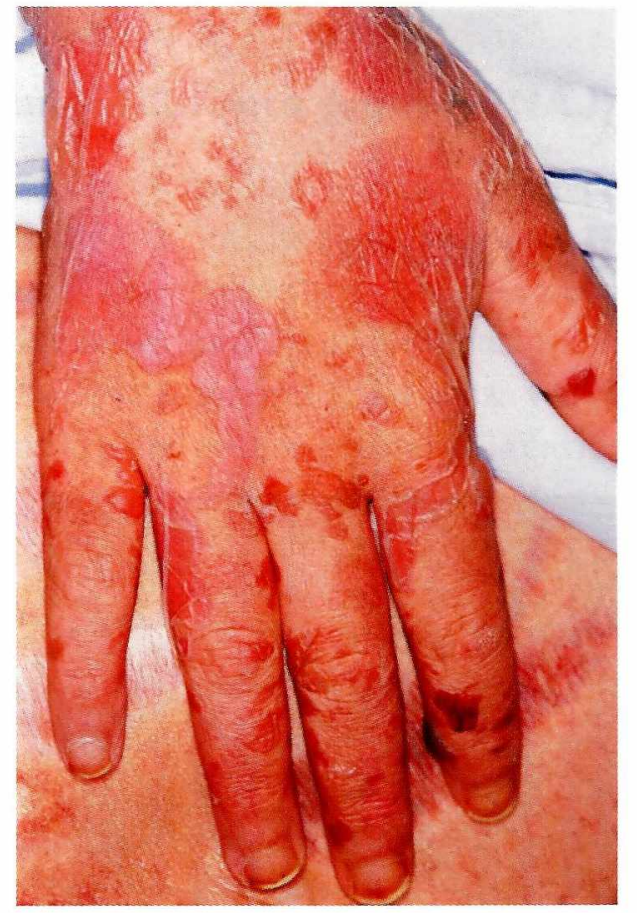

Figura 2. Lesiones ampollosas en el dorso de la mano (Cortesía del Dr. Juan J. Atuesta).



Figura 3. Gran ampolla tensa, de base eritematosa, en el dorso del pie izquierdo (Cortesía del Dr. Juan J. Atuesta).

salida para continuar el manejo ambulatorio con prednisona $60 \mathrm{mg}$ día y azatioprina $100 \mathrm{mg} /$ día. Asiste

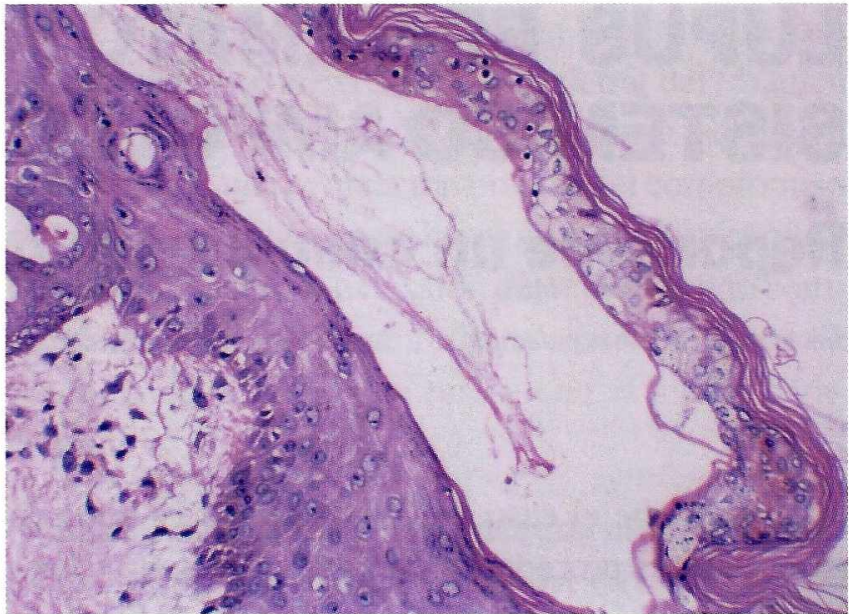

Figura 4. Aspecto microscópico de la ampolla intraepidérmica.

a control por consulta externa un mes después, encontrándose asintomática y sin lesiones ampollosas en piel.

\section{Discusión}

La presentación ampollosa es una variedad de LES. ${ }^{3,4,5}$ De acuerdo con Gammon y Briggaman ${ }^{2,6}$ los criterios para su diagnóstico son:

1. Cumplir los criterios para LES de la Asociación Americana de Reumatología (ARA).

2. Erupción ampollosa no cicatrizante adquirida que surge sobre piel expuesta y no expuesta al sol.

3. Ampollas subepidérmicas con inflamación, en especial por neutrófilos en la dermis y en la zona de la membrana basal, con depósitos de IgG, IgA, IgM y $\mathrm{C}_{3}$ en la piel perilesional

4. Autoanticuerpos circulantes para colágeno tipo VII confirmados por inmunofluorescencia indirecta en piel, Western Blood o inmunoprecipitación

5. Depósitos de inmunoglobulina codistribuídas con fibrillas ancladas de colágeno tipo VII por microscopía inmunoelectrónica.

Hay dos variedades de LES ampolloso: el tipo 1 que cumple los criterios uno a seis y el tipo 2 que satisface solo los criterios uno a cuatro. Un estudio publicado en la literatura por la Universidad Occidental de Chicago, demostró la presencia de autoanticuerpos contra múltiples componentes de la membrana basal de la 
piel, críticos para las uniones y adhesión dermoepidérmicas. Un posible mecanismo patogénico en ésta forma clínica de la enfermedad incluye la provocación de un órgano específico por la autoinmunidad sistémica y el fenómeno inmune de la "ampliación epítope". 5

Recientemente se publicó en la literatura ${ }^{2}$ el caso de un japonés de 17 años de edad que cumplió los seis criterios diagnósticos mencionados, quién recibió tratamiento inicial con dapsona pero por anormalidades en la función hepática fue suspendida. Se continuó con prednisona $60 \mathrm{mg}$ día con respuesta favorable. También existe en la literatura el reporte de un caso de una joven de 19 años en Nueva Zelanda ${ }^{7}$ con una historia de seis meses de lesiones vesicoampollosas en piel expuesta y no expuesta a la luz solar, que cumplía criterios para LES y cuya biopsia demostró ampollas subepidérmicas con un infiltrado inflamatorio de predominio neutrófilo y la demostración por inmunofluorescencia de depósitos de IgG, IgM, IgA y $\mathrm{C}_{3}$ en la unión dermoepidérmica. Recibió tratamiento con prednisona sin respuesta adecuada y posteriormente con dapsona, presentando remisión de las lesiones.

La paciente que ilustramos en éste artículo corresponde a LES ampolloso tipo 2 según la clasificación de Gammon y Briggaman, ya que cumple criterios diagnósticos de la ARA para LES. Se presentó con lesiones ampollosas sobre piel expuesta y no expuesta, inflamación predominantemente neutrófila en la dermis y presencia de $\operatorname{IgG}, \operatorname{IgA}, \operatorname{IgM}$ y $\mathrm{C}_{3}$ en el estudio de inmunofluorescencia de la piel. Al igual que los reportes de la literatura corresponde a una persona joven y los resultados del tratamiento con prednisona a dosis de $1 \mathrm{mg} / \mathrm{k} /$ día no fueron satisfactorios, por lo que se adicionó manejo con azatioprina a dosis de 100 mg día con adecuada respuesta.

\section{Resumen}

El lupus eritematoso sistémico (LES) es una enfermedad con un amplio espectro de manifestaciones sistémicas y ha sido objeto de estudio desde hace varias décadas. El cuadro clínico de los paciente con LES muestra una gran variación y por esa razón ha sido difícil desarrollar un concepto unificado de la enfermedad. Esto ha originado subgrupos que han sido definidos por constelaciones de cuadros clínicos y biológicos, cambios histológicos y anormalidades de laboratorio. ${ }^{1}$

El lupus ampolloso es una forma de presentación de LES con una combinación distintiva de cuadros clínico, histológico e inmunopatológico. ${ }^{2}$ En los últimos años ha sido reportado un pequeño número de pacientes con LES ampolloso, la mayoría de los cuales son adultos jóvenes. ${ }^{2}$ El presente caso corresponde a una paciente joven a quien se le diagnosticó LES ampolloso en nuestra institución.

\section{Bïbliografía}

1. Kunhn A. Rare manifestations of lupus erythematosus. A clinical overview. Hautarzt 2000; 51: 818-25

2. Yukiko N; Chika K. Vesicobullous systemic lupus erythematosus: A case with circulating IgG and IgA autoantibodies to type VII collagen. J Am Acad Dermatol 2002;47:

3. Fitzpatrick. Dermatología en Medicina General, $5^{\circ} \mathrm{ed}$

4. Rook, Tratado de Dermatología

5. Chan LS. Bullous systemic lupus erythematosus with autoantibodies recognizing multiple skin basement membrane components, bullous pemphigoid antigen 1, laminin -5, laminin-6, and type VII collagen. Arch Dermatol. 1999; 135: $569-73$

6. Gammon WR. Briggaman RA. Bullous SLE: a phenotypically distinctive but inmmunologically heterogeneous bullous disorder. J Invest Dermatol 1993; 100: 285-345

7. Yung A; Oakley A. Bullous systemic lupus erythematosus. Australas J Dermatol; 2000;41:234-7

Agradecimientos a los doctores Edgar Olmos y Juan Jaime Atuesta del Servicio de Dermatología del Hospital de San José. 